\title{
PER3 VNTR variant and susceptibility to smoking status/substance use disorder in a Turkish population
}

\author{
Ayse FeYda NuRSAL ${ }^{1}$ \\ https://orcid.org/0000-0001-7639-1122 \\ Pinar Cetinay Aydin² \\ https://orcid.org/0000-0002-1605-2724 \\ Mehmet Atilla Uysal ${ }^{3}$ \\ https://orcid.org/0000-0002-0430-498X \\ Mustafa Pehlivan 4 \\ https://orcid.org/0000-0002-6692-085X \\ YASEMIN OYACI ${ }^{5}$ \\ https://orcid.org/0000-0002-1338-0087 \\ Sacide Pehlivan 5 \\ https://orcid.org/0000-0003-1272-5845 \\ 1 Department of Medical Genetics, Hitit University, Faculty of Medicine, Corum, Turkey. \\ 2 Department of Psychiatry, Bakirkoy Research and Training Hospital for Psychiatry, Neurology and Neurosurgery, Istanbul, Turkey. \\ 3 University of Health Sciences, Yedikule Hospital for Chest Diseases and Thoracic Surgery Training and Research Hospital, Istanbul, Turkey. \\ 4 Department of Haematology, Gaziantep University, Faculty of Medicine, Gaziantep, Turkey. \\ ${ }_{5}^{5}$ Department of Medical Biology, Istanbul University, Istanbul Faculty of Medicine, Istanbul, Turkey.
}

Received: 05/15/2019 - Accepted: 09/15/2019

DOI: 10.1590/0101-60830000000235

\begin{abstract}
Background: Substance use and smoking exert devastating impact on sleep, especially hindering the ease of falling asleep, compromising the sleep maintenance, and distorting the sleep cycles. PERIOD genes are believed to play a role in individual differences in sleep timing by influencing circadian. Objective: The aim of this study was to ascertain whether Per3 VNTR variant affects suspectibility of individuals to substance use disorder (SUD) and smoking status in a Turkish population. Methods: A total of 549 subjects, including 212 SUD patients, 160 smoker, and 177 healthy controls, matched by ethnicity, age, and gender, were recruited in a case-control study. Genotyping of Per3 variant was performed using PCR method. Results: When the SUD, smoker groups and controls were compared in terms of 5R/5R, 5R/4R, 4R/4R genotypes, no significant difference was observed. Besides, allele frequencies of Per3 VNTR were similar among the groups. Discussion: Our data indicate that Per3 VNTR variant is not associated with the risk of SUD and smoking status in our population.
\end{abstract}

Nursal AF et al. / Arch Clin Psychiatry. 2020;47(3):71-4

Keywords: Substance use disorder, smoking status, Per3, VNTR, PCR.

\section{Introduction}

The term substance use disorders (SUDs) refers numerous disorders, such as alcohol abuse, alcoholism, drug abuse and drug addiction. These disorders affect myriad of adults and families, cost medical, economic, criminal, and social sectors of society more than 500 billion dollars, and result in more than 75,000 deaths in the U.S.1. SUDs can occur in any individual, but the risk can be higher depending on an individual's biological predisposition (e.g., genetic vulnerability), environment, and developmental stage (e.g., adolescence). Tobacco use increases the risk of major health problems and is the main cause of morbidity and mortality. The relation between cigarette smoking and many health issues, such as cardiovascular disease, pulmonary disorders, and cancer, is well known. Studies have demonstrated a clear association between poor sleep pattern and a number of adverse health behaviors, such as tobacco use, alcohol consumption, illicit drug use, suicide attempts, and unintentional injury².

Human diurnal preference is a well-established circadian phenotype with regard to the preferred timing of daily activities ${ }^{3}$. Circadian rhythms are modulated by various canonical clock genes that are extremely conserved in all species, with allelic variants affecting individual rhythms at different levels ${ }^{4}$. The circadian rhythm is controlled by these clock genes. Period homolog 3 (Per3) or Clock homologue (CLOCK), have been investigated as potential genetic correlates of chronotypes and other circadian phenotypes in humans ${ }^{5}$. A variable-number tandem repeat (VNTR) polymorphism (rs57875989) in the Per3 gene (located on chromosome 1p36.23), containing two alleles of 4 or 5 tandem 54 bp repeats (coding for a region of 18 amino acids in exon 18), has been assessed as a possible genetic factor for chronotypes and other circadian phenotypes ${ }^{6}$. Some research show that circadian gene variants might modify the function of these genes, hence modifying diurnal preference and sleep-wake patterns ${ }^{7}$.

Because sleeping impairments are seen more frequently in this disorders, we aimed to ascertain whether Per3 VNTR variant affects susceptibility of individuals to substance use disorder (SUD) and smoking status in a Turkish population

\section{Methods}

\section{Study population}

This case-control association study included 212 patients with SUD, 160 smokers, and 177 healthy controls. The subjects with SUD were selected from among the individuals with positive urine test in the Department of Psychiatry, Bakirkoy Research and Training Hospital for Psychiatry Hospital, Istanbul Turkey. All SUD patients in the study met DSM-IV (American Psychiatry Association) criteria ${ }^{8}$. Smoker group was selected from the Department of Chest Diseases, Yedikule Hospital for Chest Diseases and Thoracic Surgery Training and 
Research Hospital, Istanbul, Turkey. Smoker group consisted of active smokers. These subjects were defined as those who had previously smoked more than one cigarette per day but had quit smoking for more than one year. The degree of smoking was evaluated by the scores on the Fagerström Test for Nicotine Dependence (FTND) 9 . Control group was recruited from "non-smokers" were defined as those who had smoked less than one cigarette per day for no more than 1 year during their lifetime and subjects who did not have a personal history of any psychiatric disorder and chronic use of any drugs. All subjects were of Turkish origin. Before enrollment, signed informed consent was obtained from each participant. The study protocols were performed according to the principles of the Declaration of Helsinki. This study was approved by the Ethics Committees of the Istanbul University, Istanbul Medical Faculty.

\section{Genotyping}

Peripheral blood was taken from subjects, and DNA was isolated using a standard salting out method ${ }^{10}$. Polymerase chain reaction (PCR) was performed to amplify the exon 18 using the primers: upstream, 5'-CCTTGGTTGACCACAGGTAA-3' and downstream, 5'-CCACTACCTGATGCTGCTGA-3' (amplification conditions: $95^{\circ} \mathrm{C}$ for 30 seconds, $60^{\circ} \mathrm{C}$ for 30 seconds, $72{ }^{\circ} \mathrm{C}$ for 45 seconds, recycle for 28 cycles, $72{ }^{\circ} \mathrm{C}$ for $10 \mathrm{~min}, 48 \mathrm{C}$ forever), and in $40 \mathrm{ml}$ mixture containing $3.2 \mathrm{~mL}(2.5 \mathrm{mM})$ deoxyribonucleotide triphosphate, 3.2 $\mathrm{mL}(25 \mathrm{mM}) \mathrm{Mg}^{+2}, 0.4 \mathrm{~mL}(5 \mathrm{U} / \mathrm{mL})$ Taq polymerase, $4 \mathrm{~mL} \mathrm{10}$ buffer; $25.4 \mathrm{~mL} \mathrm{H} 2 \mathrm{O}, 1 \mathrm{~mL}$ of each primer $(10 \mathrm{mM})$ and $1.8 \mathrm{~mL}(50$ $\mathrm{ng} / \mathrm{mL}$ ) DNA template. Three percent agarose gel electrophoresis was used to identify whether individuals were heterozygous or homozygous for either of the Per 3 repeat alleles.

\section{Statistical analysis}

The genotype distribution and allele frequency of the Per3 VNTR variant in the control and patient groups were compared using Chisquare test. The Hardy-Weinberg equilibrium (HWE) was calculated using the de Finetti program (Online HWE and Association TestingInstitut für Humangenetik, Munich, Germany). Odds ratio (OR) and $95 \%$ confidence intervals (CIs) were estimated using the binary logistic regression method. $p$ values less than $p<0.05$ were considered statistically significant.

\section{Results}

Allelic and genotypic distributions of the Per3 VNTR variant in subjects and controls are shown in Table 1. Among the 212 SUD patients, $16.6 \%$ were identified with the $5 \mathrm{R} / 5 \mathrm{R}$ genotype, $45.7 \%$ with the $5 \mathrm{R} / 4 \mathrm{R}$ genotype and $37.7 \%$ with the $4 \mathrm{R} / 4 \mathrm{R}$ genotype; among the 160 smoker subjects, $20 \%$ were identified with the $5 \mathrm{R} / 5 \mathrm{R}$ genotype, $38.2 \%$ with the $5 \mathrm{R} / 4 \mathrm{R}$ genotype and $41.8 \%$ with the $4 \mathrm{R} / 4 \mathrm{R}$ genotype; among the 177 control subjects, $15.8 \%$ were identified with the $5 \mathrm{R} / 5 \mathrm{R}$ genotype, $43.6 \%$ with the $5 \mathrm{R} / 4 \mathrm{R}$ genotype and $40.6 \%$ with the $4 \mathrm{R} / 4 \mathrm{R}$ genotype. The genotype distribution of Per3 VNTR variant did not show any statistically significant differences between subjects with SUD, smokers and controls ( $p>0.05)$. Also, allele frequencies of Per3 VNTR were similar between the groups. The observed genotype counts deviated significantly from those expected in smoker group according to the HWE for Per3 VNTR variant.

\section{Discussion}

Circadian rhythms are universal in all living organisms and almost all physiological functions, most remarkably sleep and wake cycles, show circadian rhythmicity. Circadian rhythms occur intrinsically and remain in the lack of environmental time cues. The suprachiasmatic nucleus ( $\mathrm{SCN}$ ), a structure located in the anterior hypothalamus is the region of a master circadian clock ${ }^{11}$. Essentially every physiological and behavioral parameter follows the nearly 24-hour (circadian) rhythms, the sleep/wake cycle being the most evident. Sleep is a dynamic and complex set of physiological conditions that plays a fundamental role in life. Sleep is characterized by a alignment of central nervous system characteristics, such as an unequalled profile of brain-wave activity, eye movements, and muscle activity ${ }^{12}$.

The chronic abuse of substances may arise due to a desire to relieve negative affect, including anxiety or depressed mood, to palliate physical pain, to improve sleep, or to increase experience of pleasure. After dependence has developed, withdrawal from the substance can result in many unpleasant consequences. One of the most common results of the use of and withdrawal from substances of abuse is sleep disturbance. It has been reported that sleep disturbances occur in up to $90 \%$ of alcoholic individuals ${ }^{13}$. The correlation between substance use and sleep problems seems to be bidirectional ${ }^{14}$ with sleep problems enhancing risk for SUDs ${ }^{15}$, and acute and chronic substance use causing acute and chronic sleep problems ${ }^{16}$. Most studies in this area are based on surveys and demonstrate that smokers subjectively report sleep problems ${ }^{17}$. Investigating large populations of smokers, a subjectively decreased quality of sleep and more insomnia-like symptoms (decreased sleep quality, longer time for sleep onset, less restorative sleep; compared with non-smokers have been found ${ }^{18,19}$. These impairments are ascribed the stimulating effect of nicotine ${ }^{20,21}$.

The circadian rhythm is subject to coordinated modulation of clock genes including Arntl, Dbp and Csnk1d, and the period homologs Per1, Per2 and Per322. One of the main parts of the endogenous clock system is gene Per 3 that is periodically transcribed contributing to generate 24 -h cycles of physiological and metabolic processes in certain cells. The Per 3 gene from the protein PERIOD family has a pleiotropic effect on the cell clock mechanism, particularly in the modulation of sleep homeostasis and chronotype preferences ${ }^{6}$. The principal role of Per3 involves regulating sleep/wake timing and sleep homeostasis ${ }^{23}$.

Table 1. Genotypes and alleles distribution of Per3VNTR variant in cases and controls

\begin{tabular}{|c|c|c|c|c|c|c|}
\hline Per3VNTR & SUD group & Smoker group & Control group & $\mathrm{OR}^{*}$ & $\% 95 \mathrm{Cl}^{*}$ & $P$ \\
\hline Genotypes & $\mathrm{n}: 212(\%)$ & n: $160(\%)$ & n: $177(\%)$ & & & \\
\hline $5 R / 5 R$ & 35 (16.6) & $32(20)$ & 28 (15.8) & $\begin{array}{l}0.950^{\mathrm{a}} \\
0.752^{\mathrm{b}}\end{array}$ & $\begin{array}{l}0.552-1.635^{a} \\
0,430-1.315^{b}\end{array}$ & $\begin{array}{l}0.854^{\mathrm{a}} \\
0.316^{\mathrm{b}}\end{array}$ \\
\hline $5 R / 4 R$ & $97(45.7)$ & 61 (38.2) & $77(43.6)$ & $\begin{array}{l}0.913^{\mathrm{a}} \\
1.250^{\mathrm{b}} \\
\end{array}$ & $\begin{array}{l}0.611-1.364^{a} \\
0.808-1.933^{b}\end{array}$ & $\begin{array}{l}0.656^{\mathrm{a}} \\
0.316^{\mathrm{b}}\end{array}$ \\
\hline $4 R / 4 R$ & $80(37.7)$ & $67(41.8)$ & $72(40.6)$ & $\begin{array}{l}1.131^{\mathrm{a}} \\
0.952^{\mathrm{b}}\end{array}$ & $\begin{array}{l}0.752-1.703^{a} \\
0.616-1.469^{b}\end{array}$ & $\begin{array}{l}0.554^{a} \\
0.824^{b}\end{array}$ \\
\hline \multicolumn{7}{|l|}{ Alleles } \\
\hline \begin{tabular}{|l}
$5 \mathrm{R}$ \\
$4 \mathrm{R}$ \\
\end{tabular} & $\begin{array}{l}167(39.3) \\
257(60.7) \\
\end{array}$ & $\begin{array}{l}125(39.1) \\
195(60.9)\end{array}$ & $\begin{array}{l}133(37.5) \\
221(62.5) \\
\end{array}$ & $\begin{array}{l}0.926^{\mathrm{a}} \\
0.939^{\circ}\end{array}$ & $\begin{array}{l}0.693-1.238^{a} \\
0.688-1.281^{b}\end{array}$ & $\begin{array}{l}0.604^{\mathrm{a}} \\
0.691^{\mathrm{b}}\end{array}$ \\
\hline HWEp & 0.543 & 0.011 & 0.333 & & & \\
\hline
\end{tabular}

*Pearson chi-square test; a: SUD group versus control group; b: Smoker group versus control; HWE: Hardy-Weinberg equilibrium. The results that are statistically significant are shown in boldface. 
The most investigated variant in Per3 gene is a biallelic VNTR polymorphism in a region encoding an assumed phosphorylation site $^{24}$. In humans, this primate-specific polymorphism consists of a 54-nucleotide unit that is repeated 4 (Per 4 allele) or 5 (Per 5 allele) times ${ }^{25}$. The longer, 5-repeat allele has been related with enhanced morning preference, higher sleep propensity and poorer cognitive performance in response to sleep deprivation, while the 4-repeat allele is related with eveningness. Individuals with the Per3 5/5 genotype displayed an extreme diurnal preference-earlier wake-up and sleep-times ${ }^{26}$. Per3 VNTR has been associated with multiple phenotypic parameters, such as diurnal preference, myocardial infarction, sleep disturbances in multiple sclerosis, mood disorders, and also with an increased breast cancer risk $6,25,27-29$.

While the PERIOD family could be considered as possible modulators of sleep function, we focused on the gene for Per3 VNTR variant and SUD/smoking status and we aimed to clarify the impact of the Per3 VNTR variant on susceptibility SUD and smoking status in a Turkish population. This is the first study carried out in the Turkish population regarding the association Per3 VNTR variant and SUD/smoking status. Some studies have proposed the role of Per2 in alcohol consumption behavior in humans and animal models. Spanagel et al. showed that a SNP in Per2 (rs56013859) was associated with high levels of alcohol use in alcohol dependent patients ${ }^{30}$. Gamsby et al. reported that mutation of either Per1 or Per2, as well as mutations of both genes, increases ethanol intake and reinforcement in an ethanol-preferring mouse model ${ }^{31}$. Malison et al. found that there was no link between CLOCK, Per1 or Per2 variants and susceptibility to cocaine addiction ${ }^{32}$. In another study, it was reported that Per2 VNTR variant was significantly associated with vulnerability to cocaine addiction ${ }^{33}$. Brower et al. evaluated that the association Per3 genotype and insomnia severity in subjects with alcohol dependence ${ }^{34}$. They found that the subjects with the Per3 (4/4) genotype had the greatest severity of insomnia symptoms. In this study, we did not reveal any association between the Per3 VNTR and both SUD and smoking status. Also, allele frequencies were similar in groups.

As far as we know, this is the first study reporting the association of Per3 VNTR variant, located in the intron, with the SUD and smoking status. Our results suggest the Per3 VNTR variant was not associated with SUD and smoking status in a sample from the Turkish population. But distribution of variants varies significantly among different ethnic groups, this may contribute to the observed differences in ethnicity-dependent prevalence. Therefore additional studies on larger population will be necessary to confirm our results and to provide further insights into cellular clock gene circadian mechanism underlying addiction and/or smoking status.

\section{Conflict of interest}

The authors confirm that this article's content has no conflicts of interest.

\section{Financial disclosure}

The study was partially supported by Istanbul University BAP-ONAP (47815) program.

\section{Informed consent}

Written informed consent was obtained from subjects and patients who participated in this study.

\section{References}

1. Conroy DA, Arnedt JT. Sleep and substance use disorders: an update. Curr Psychiatry Rep. 2014;16(10):487.

2. Zhabenko O, Austic E, Conroy DA, Ehrlich P, Singh V, Epstein-Ngo Q, et al. Substance Use as a Risk Factor for Sleep Problems Among Adolescents Presenting to the Emergency Department. J Addict Med. 2016;10(5):331-8.
3. Adan A, Archer SN, Hidalgo MP, Di Milia L, Natale V, Randler C. Circadian typology: a comprehensive review. Chronobiol Int. 2012;29(9):1153-75.

4. Brown SA, Kunz D, Dumas A, Westermark PO, Vanselow K, Tilmann-Wahnschaffe A, et al. Molecular insights into human daily behavior. Proc Natl Acad Sci U S A. 2008;105(5):1602-7.

5. Barclay NL, Eley TC, Mill J, Wong CC, Zavos HM, Archer SN, et al. Sleep quality and diurnal preference in a sample of young adults: associations with 5HTTLPR, PER3, and CLOCK 3111. Am J Med Genet B Neuropsychiatr Genet. 2011;156B(6):681-90.

6. Archer SN, Carpen JD, Gibson M, Lim GH, Johnston JD, Skene DJ, et al. Polymorphism in the PER3 promoter associates with diurnal preference and delayed sleep phase disorder. Sleep. 2010;33(5):695-701.

7. Hida A, Kitamura S, Katayose Y, Kato M, Ono H, Kadotani H, et al. Screening of clock gene polymorphisms demonstrates association of a PER3 polymorphism with morningness-eveningness preference and circadian rhythm sleep disorder. Sci Rep. 2014;4:6309.

8. Hasin DS, O’Brien CP, Auriacombe M, Borges G, Bucholz K, Budney A, et al. DSM-5 criteria for substance use disorders: Recommendations and rationale. Am J Psychiatry 2013;170(8):834-51.

9. Heatherton TF, Kozlowski LT, Frecker RC, Fagerström KO. The Fagerström test for nicotine dependence: A revision of the Fagerström tolerance questionnaire. Br J Addict. 1991;86(9):1119-27.

10. Miller SA, Dykes DD, Polesky HF. A simple salting outprocedure for extracting DNA from human nucleated cells. Nucleic Acids Res. 1988:16(3):215.

11. Stephan FK, Zucker IC. Circadian rhythms in drinking behavior and locomotor activity of rats are eliminated by hypothalamic lesions. Proc Natl Acad Sci U S A. 1972;69(6):1583-6

12. Colrain IM. Sleep and the brain. Neuropsychol Rev. 2011;21(1):1-4.

13. Cohn T, Foster J, Peters T. Sequential studies of sleep disturbance and quality of life in abstaining alcoholics. Addict Biol. 2003;8(4):455-62.

14. Johnson EO, Breslau N. Sleep problems and substance use in adolescence. Drug Alcohol Depend 2001;64(1):1-7.

15. Breslau N, Roth T, Rosenthal L, Andreski P. Sleep disturbance and psychiatric disorders: a longitudinal epidemiological study of young adults. Biol Psychiatry. 1996;39(6):411-8.

16. Burke CK, Peirce JM, Kidorf MS, Neubauer D, Punjabi NM, Stoller KB, et al. Sleep problems reported by patients entering opioid agonist treatment. J Subst Abuse Treat. 2008;35(3):328-33.

17. Conway SG, Roizenblatt SS, Palombini L, Castro LS, Bittencourt LR, Silva RS, et al. Effect of smoking habits on sleep. Braz J Med Biol Res. 2008;41(8):722-7.

18. Riedel BW, Durrence HH, Lichstein KL, Taylor DJ. The relation between smoking and sleep: the influence of smoking level, health and psychological variables. Behav Sleep Med. 2004;2(1):63-78.

19. Sabanayagam C, Shankar A. The association between active smoking, smokeless tobacco, second-hand smoke exposure and insufficient sleep. Sleep Med. 2011;12(1):7-11.

20. Wetter DW, Young TB. The relation between cigarette smoking and sleep disturbance. Prev Med. 1994;23(3): 328-34.

21. Soldatos CR, Kales JD, Scharf MB, Bixler EO, Kales A. Cigarette smoking associated with sleep difficulty. Science. 1980;207(4430):551-3.

22. McClung CA. Circadian rhythms, the mesolimbic dopaminergic circuit, and drug addiction. ScientificWorldJournal. 2007;7:194-202.

23. Dijk DJ, Archer SN. PERIOD3, circadian phenotypes, and sleep homeostasis. Sleep Med Rev. 2010;14(3):151-60.

24. Ebisawa T, Uchiyama M, Kajimura N, Mishima K, Kamei Y, Katoh M, et al. Association of structural polymorphisms in the human period3 gene with delayed sleep phase syndrome. EMBO Rep. 2001;2(4):342-6.

25. Lipkova J, Splichal Z, Bienertova-Vasku JA, Jurajda M, Parenica J, Vasku A, et al. Period3 VNTR polymorphism influences the time-of-day pain onset of acute myocardial infarction with ST elevation. Chronobiol Int. 2014;31(8):878-90.

26. Archer SN, Robilliard DL, Skene DJ, Smits M, Williams A, Arendt J, et al. A length polymorphism in the circadian clock gene Per3 is linked to delayed sleep phase syndrome and extreme diurnal preference. Sleep. 2003;26(4):413-5.

27. Golalipour M, Maleki Z, Farazmandfar T, Shahbazi M. PER3 VNTR polymorphism in Multiple Sclerosis: A new insight to impact of sleep disturbances in MS. Mult Scler Relat Disord. 2017;17:84-86. 
28. Dallaspezia S, Lorenzi C, Pirovano A, Colombo C, Smeraldi E, Benedetti F. Circadian clock gene Per3 variants influence the postpartum onset of bipolar disorder. Eur Psychiatry. 2011;26(3):138-40.

29. Zhu Y, Brown HN, Zhang Y, Stevens RG, Zheng T. Period3 structural variation: A circadian biomarker associated with breast cancer in young women. Cancer Epidemiol Biomarkers Prev. 2005;14(1):268-70.

30. Spanagel R, Pendyala G, Abarca C, Zghoul T, Sanchis-Segura C, Magnone MC, et al. The clock gene Per2 influences the glutamatergic system and modulates alcohol consumption. Nat Med. 2005;11(1):35-42.

31. Gamsby JJ, Templeton EL, Bonvini LA, Wang W, Loros JJ, Dunlap JC, et al. The circadian Per1 and Per2 genes influence alcohol intake, reinforcement, and blood alcohol levels. Behav Brain Res. 2013;249:15-21.
32. Malison RT, Kranzler HR, Yang BZ, Gelernter J. Human clock, PER1 and PER2 polymorphisms: lack of association with cocaine dependence susceptibility and cocaine-induced paranoia. Psychiatr Genet. 2006;16(6):245-9.

33. Shumay E, Fowler JS, Wang GJ, Logan J, Alia-Klein N, Goldstein RZ, et al. Repeat variation in the human PER2 gene as a new genetic marker associated with cocaine addiction and brain dopamine D2 receptor availability. Transl Psychiatry. 2012;2:e86.

34. Brower KJ, Wojnar M, Sliwerska E, Armitage R, Burmeister M. PER3 polymorphism and insomnia severity in alcohol dependence. Sleep. 2012;35(4):571-7. 